\title{
Inadequacy of vitamins and minerals among high-school pupils in Ouarzazate, Morocco
}

\author{
Karim Anzid ${ }^{1, *}$, Abdellatif Baali ${ }^{1}$, Patrice Vimard ${ }^{2}$, Susan Levy-Desroches ${ }^{3}$, \\ Mohamed Cherkaoui ${ }^{1}$ and Pilar Montero López ${ }^{4}$ \\ 'Department of Biology, Laboratory of Human Ecology, Cadi Ayyad University, Faculty of Sciences Semlalia, \\ Bvd Prince My Abdellah, BP 2390, 40000 Marrakesh, Morocco: ${ }^{2}$ Population-Environment-Development \\ Laboratory, University of Provence, Marseille, France: ${ }^{3}$ Consultant Epidemiologist, Luxembourg: ${ }^{4}$ Unidad de \\ Antropología, Departamento de Biología, Facultad de Ciencias, Universidad Autónoma de Madrid, Madrid, Spain
}

Submitted 16 September 2012: Final revision received 14 June 2013: Accepted 8 July 2013: First published online 19 August 2013

\begin{abstract}
Objective: To assess micronutrient intakes and the prevalence of inadequacy in a sample of high-school pupils in Ouarzazate, Morocco.

Design: Food records were compiled over three non-consecutive days by pretrained pupils. Micronutrient intakes were estimated using the DIAL software, adapted to include foods commonly eaten in Morocco. The prevalence of inadequacy was estimated by the proportion of individuals with intakes below the Estimated Average Requirement (EAR) for vitamins $\mathrm{B}_{12}, \mathrm{~A}$ and $\mathrm{K}$, thiamin, riboflavin, niacin, pyridoxine, folate, ascorbic acid, iodine, $\mathrm{Ca}, \mathrm{Mg}$ and $\mathrm{P}$; below the Adequate Intake (AI) level for pantothenic acid, biotin, $\mathrm{Na}$ and $\mathrm{K}$; and using the probability approach for Fe. Data were adjusted for intra-individual variation with exclusion of under-reporters.

Setting: Ouarzazate, a semi-urban region situated on the southern slopes of the High Atlas with little industrial development but an important tourism sector.

Subjects: A self-selected sample of 312 pupils aged 15-19 years from the five public high schools. After exclusion of under-reporters, 293 remained for analysis.

Results: The highest proportions of below-EAR/AI intakes were seen for pantothenic acid (girls $85 \cdot 1 \%$, boys $78 \cdot 0 \%$ ), biotin (boys $83 \cdot 1 \%$, girls $79 \cdot 4 \%$ ), thiamin (boys 66.9\%), folate (girls $93.1 \%$, boys $74.6 \%$ ), iodine (boys $94.9 \%$, girls $88.0 \%$ ) and $\mathrm{Ca}$ (girls $83 \cdot 4 \%$, boys $74.6 \%$ ). Na intake was generally in excess whereas K intake was below the AI level. In general, girls had better-quality diets than boys, who appeared to consume more 'empty calories'.

Conclusions: Our findings suggest that in this population of Moroccan adolescents, nutritional intervention and educational strategies are needed to promote healthy eating habits and correct micronutrient inadequacies. To provide reliable and precise estimates of nutrient intakes, an update of Moroccan food composition databases is urgently needed. We recommend that national authorities address these issues.
\end{abstract}

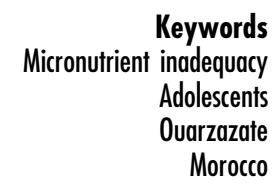

Micronutrient deficiencies - 'hidden hunger' - represent a significant public health problem in many developing countries $^{(1)}$. Morocco is undergoing a nutritional transition in which we see deficiencies coexisting with obesity-related diseases in the same household ${ }^{(2-5)}$.

A period of undoubted nutritional interest ${ }^{(6,7)}$, adolescence is one of the most active growth periods, during which the requirements for vitamins, minerals and trace elements increase substantially ${ }^{(8)}$. Over $20 \%$ of total growth in stature and up to $50 \%$ of adult bone mass are acquired during adolescence ${ }^{(9)}$, with a corresponding 50\% increase in Ca requirements. The growing red cell mass $(\mathrm{Hb})$, muscle development (myoglobin) and menstrual blood loss induce an increase in Fe demands of up to $15 \%{ }^{(10)}$.
However, growth and maturation in adolescence may be adversely affected by factors such as inadequate nutrient intakes, infections and chronic diseases. The increasingly early age of onset of chronic conditions such as obesity and type 2 diabetes points to the importance of surveillance and healthy lifestyle education for children and teenagers ${ }^{(11)}$. Appropriate nutrition is thus crucial for adolescents, not only to meet their increased growth requirements but also to prevent chronic diseases in adulthood. Unfortunately, very little information exists on vitamin and mineral intakes in adolescents or their nutritional status ${ }^{(12)}$, particularly in developing countries ${ }^{(13)}$. Better knowledge of dietary intakes in adolescents would help health professionals provide optimal advice to 
individuals and also serve as a basis for the development of health promotion strategies ${ }^{(14)}$.

The present study set out to assess the mean usual daily intakes of micronutrients in high-school pupils aged 15-19 years living in the Ouarzazate municipality in southern Morocco, with the aim of defining the proportion of pupils particularly at risk of nutrient inadequacy for a selected range of micronutrients and assessing the contribution of food groups to four micronutrients (thiamin, folate, $\mathrm{Ca}$ and $\mathrm{Na}$ ).

\section{Experimental methods}

\section{Participants and data collection}

A dietary study was conducted between November 2007 and January 2008 in a self-selected sample of 327 secondaryschool pupils aged 15-20 years. Pupils were recruited from the five public high schools in Ouarzazate, a semiurban region situated on the southern slopes of the High Atlas with little industrial development but an important tourism sector. The target population consisted of the 4605 pupils enrolled in high schools in Ouarzazate in the 2007-2008 school year. Our aim was to recruit about $20 \%$ of the target population and recruiting stopped when this number was attained. A total of 921 pupils gave their consent to participate in the research, but for the present analyses only those who completed the three $24 \mathrm{~h}$ food logs were included. The 327 pupils in the final study sample represent $7 \cdot 1 \%$ of the target population.

After training, the pupils recorded all foods and quantities consumed, as well as details of ingredients and cooking methods (e.g. boiled, grilled, fried), in a food consumption logbook over three non-consecutive days (Tuesday, Friday and Sunday). Common household measures (e.g. cup, coffee glass, tea glass, water glass, teaspoon, tablespoon) recorded by the pupils were transformed into quantitative units by weighing using precision electronic scales. Composite dishes were reconstituted in the test kitchen and weighed before and after cooking according to the recipes recorded by the pupils.

\section{Measures of nutrient inadequacy}

Nutrient intakes were estimated from the analysis of the 327 food logbooks ( $\times 3 \mathrm{~d}=981 \mathrm{~d})$ using the DIAL program, version $1 \cdot 0^{(15)}$. This software is based on several food composition tables, including Spanish tables ${ }^{(16,17)}$ and those of the US Department of Agriculture ${ }^{(18)}$. The food composition table was extended to include typical Moroccan foods and dishes (seasonings and condiments, tagines, couscous, harira, msemmen, etc. $)^{(19)}$ with the help of the FAO composition table for use in Africa ${ }^{(20)}$.

The different food composition tables used took fortified foods into account. If a respondent mentioned a fortified food (by brand name), we checked the chemical composition and its concordance with the DIAL program.
If necessary, the chemical composition was modified. However, respondents rarely mentioned whether a food was fortified or brand names. The DIAL program assumes an iodine content of $44 \mu \mathrm{g}$ in $100 \mathrm{~g}$ of salt. The program also allows the creation of new foods, for example 'iodised salt' with a content of about $30 \mathrm{mg} / \mathrm{kg}$, as mentioned on the labels of salt packages sold in local shops. Taking into account the greater bioavailability of synthetic folic acid, the DIAL program calculates folate intake as $\mu \mathrm{g}$ DFE (dietary folate equivalents; [food folate $+(1.7 \times$ synthetic folic acid content $)])$.

To remove the effects of day-to-day variation, which was minimal, the measurement error model developed by the Department of Epidemiology of the German Institute of Human Nutrition Potsdam-Rehbrücke (DIfE version 1.0) ${ }^{(21)}$ was applied to the usual intake. A total of thirty-four pupils were excluded from the analyses: fifteen were over 19 years of age and nineteen (eight boys and eleven girls) were identified as under-reporters according to the method described by Goldberg and Black ${ }^{(22)}$, having a ratio of energy intake to BMR less than or equal to $0 \cdot 87$, leaving 293 participants ( 175 girls and 118 boys aged $15-19$ years) for analysis.

Micronutrient intakes were compared with the recommendations of the Food and Nutrition Board, Institute of Medicine ${ }^{(23-28)}$. We opted to use the Institute of Medicine Dietary Reference Intakes since they are in general more comprehensive than the FAO/WHO Dietary Reference Intakes, which do not provide the Estimated Average Requirement (EAR) values we required for our analyses. The EAR represents the median daily nutrient intake level estimated to meet the requirements of half the healthy individuals in a particular life-stage and gender group ${ }^{(23)}$. The requirement is the amount of nutrient necessary to satisfy the functional needs of the body, ensure nutrient stores and prevent disease in the long term.

To determine the prevalence of inadequate intake, we elected to use the EAR cut-point method recommended and described in detail by the Institute of Medicine ${ }^{(29)}$, validated by De Lauzon et $a l .^{(30)}$ and recently applied in France by Touvier et $a l^{(31)}$, as this is the method commonly used in North America, France and French-speaking countries and the one with which we are most familiar.

For some nutrients, there was insufficient scientific evidence to establish an EAR, so an Adequate Intake (AI) level was set instead. The AI is defined as 'the recommended average daily intake value based on observed or experimentally determined approximations or estimates of nutrient intake by a group (or groups) of healthy people that are assumed to be adequate - used when an RDA cannot be determined, ${ }^{,(28)}$. As a recommended intake for individuals, the AI is expected to meet or exceed the amount needed to maintain a defined nutritional state or criterion of adequacy in almost all members of an apparently healthy population ${ }^{(32)}$. For Fe, we used the probability approach recommended by the Institute of Medicine ${ }^{(26)}$, since the presence of menstruating 
women skews the requirement distribution curve and renders the EAR cut-point method inappropriate.

For vitamin A, vitamin $\mathrm{K}$, thiamin, riboflavin, niacin, pyridoxine, folate, vitamin $\mathrm{B}_{12}$, ascorbic acid, iodine, $\mathrm{Ca}$, $\mathrm{Mg}$ and $\mathrm{P}$, the prevalence of inadequacy was estimated by the percentage of individuals with median intakes below the EAR. For pantothenic acid, biotin, $\mathrm{Na}$ and $\mathrm{K}$, we calculated the percentage of individuals with median intakes below the $\mathrm{AI}$ and for Fe the percentage with inadequate intakes using the probability approach.

Individuals 'particularly at risk' of nutrient inadequacy were defined as those for whom the 95\% confidence interval of the prevalence of inadequacy lay above $50 \%$ and included a value greater than or equal to $70 \%{ }^{(31)}$.

\section{Statistical analysis}

All statistical analyses were performed using the statistical software package SPSS version $10 \cdot 0 \cdot 5$. Descriptive statistical analysis techniques were used to test distributions of means. The non-parametric Mann-Whitney $U$ test was used to compare medians between groups. The level of significance applied to statistical tests was $<0 \cdot 05$. Percentage contribution of twelve food groups to the intake of certain micronutrients was calculated for the total study sample and separately for boys and girls. Differences between sexes were tested with the Pearson $\chi^{2}$ test.

\section{Results}

All results reported below exclude the nineteen underreporters. There were no statistically significant differences in the findings before and after exclusion of the under-reporters.

\section{Usual daily intakes of vitamins and minerals}

There were significant sex-related differences in the median usual intakes of certain vitamins and minerals (Table 1). Absolute intakes (unadjusted for energy intake) of water-soluble vitamins in boys were consistently higher than in girls, with the exception of the vitamins riboflavin and biotin (identical in both sexes) and ascorbic acid (higher intake in girls). For fat-soluble vitamins, the absolute intake of vitamin $\mathrm{K}$ was higher in boys than in girls, whereas the opposite was observed for vitamin A. Absolute intakes of minerals were also systematically higher in boys than in girls, except for iodine (identical) and $\mathrm{Ca}$ (higher in boys but not statistically significant). Total energy intake was statistically significantly higher in boys than in girls (8.96 (SD 1.64$) \mathrm{MJ} / \mathrm{d} v .8 \cdot 14$ (SD 1.83) MJ/d, $P<0 \cdot 001$ ).

When nutrient densities - nutrient intakes adjusted for total energy intake - were considered, the results were quite different (Table 2). Nutrient densities of watersoluble vitamins were higher in girls than in boys, except for thiamin, riboflavin and niacin (identical in both sexes) and folate and vitamin $\mathrm{B}_{12}$ (higher intake in boys). The most marked difference was seen for ascorbic acid: girls had a mean density of $13.6 \mu \mathrm{g} / \mathrm{MJ}$ compared with $10.0 \mu \mathrm{g} / \mathrm{MJ}$ for boys. For fat-soluble vitamins, the nutrient densities of vitamins $\mathrm{A}$ and $\mathrm{K}$ were higher in girls than in boys, in particular vitamin A, with a mean density of $108.0 \mu \mathrm{g}$ RE (retinol equivalents)/MJ in girls and $91 \cdot 3 \mu \mathrm{g} \mathrm{RE} / \mathrm{MJ}$ in boys. The nutrient densities of iodine, $\mathrm{Ca}$ and $\mathrm{K}$ were higher in girls than in boys, those of $\mathrm{P}$ and $\mathrm{Na}$ were identical and those of $\mathrm{Fe}$ and $\mathrm{Mg}$ were higher in boys.

Table 1 Mean and median usual daily intakes of vitamins and minerals by sex in Moroccan pupils aged 15-19 years, November 2007-January 2008

\begin{tabular}{|c|c|c|c|c|c|c|c|c|c|c|c|}
\hline & \multicolumn{3}{|c|}{ Total $(n$ 293) } & \multicolumn{3}{|c|}{ Boys ( $n$ 118) } & \multicolumn{3}{|c|}{ Girls (n 175) } & \multirow[b]{2}{*}{$Z$} & \multirow[b]{2}{*}{$P$} \\
\hline & Mean & SD & Median & Mean & SD & Median & Mean & SD & Median & & \\
\hline \multicolumn{12}{|l|}{ Water-soluble vitamins } \\
\hline Thiamin (mg/d) & 0.9 & $0 \cdot 2$ & 0.9 & 0.9 & $0 \cdot 1$ & 0.9 & 0.9 & 0.2 & $0 \cdot 8$ & $3 \cdot 2^{* *}$ & 0.002 \\
\hline Riboflavin (mg/d) & $1 \cdot 2$ & $0 \cdot 3$ & $1 \cdot 2$ & $1 \cdot 3$ & $0 \cdot 3$ & $1 \cdot 2$ & $1 \cdot 2$ & 0.3 & $1 \cdot 2$ & $1 \cdot 3^{\mathrm{NS}}$ & 0.178 \\
\hline Niacin (NE/d) & $22 \cdot 4$ & $3 \cdot 8$ & $22 \cdot 2$ & $24 \cdot 1$ & $3 \cdot 2$ & $24 \cdot 0$ & $21 \cdot 2$ & $3 \cdot 6$ & $20 \cdot 8$ & $6 \cdot 4^{\star \star *}$ & 0.000 \\
\hline Pantothenic acid $(\mathrm{mg} / \mathrm{d})$ & $4 \cdot 2$ & $0 \cdot 7$ & $4 \cdot 2$ & $4 \cdot 4$ & $0 \cdot 6$ & $4 \cdot 3$ & $4 \cdot 1$ & 0.8 & $4 \cdot 1$ & $2 \cdot 8^{\star \star}$ & 0.006 \\
\hline Pyridoxine (mg/d) & $1 \cdot 4$ & $0 \cdot 2$ & $1 \cdot 4$ & $1 \cdot 5$ & $0 \cdot 1$ & $1 \cdot 5$ & $1 \cdot 4$ & 0.2 & $1 \cdot 4$ & $3 \cdot 8^{* \star *}$ & 0.000 \\
\hline Biotin $(\mu \mathrm{g} / \mathrm{d})$ & $19 \cdot 9$ & $6 \cdot 2$ & $18 \cdot 9$ & $19 \cdot 5$ & $6 \cdot 4$ & $18 \cdot 7$ & $20 \cdot 1$ & $6 \cdot 0$ & $19 \cdot 1$ & $1 \cdot 0^{\mathrm{NS}}$ & 0.277 \\
\hline Folate ( $\mu \mathrm{g}$ DFE/d) & $248 \cdot 3$ & $48 \cdot 6$ & $245 \cdot 1$ & $269 \cdot 4$ & $49 \cdot 2$ & $261 \cdot 8$ & $234 \cdot 1$ & $42 \cdot 7$ & $229 \cdot 8$ & $5 \cdot 8^{\star \star \star}$ & 0.000 \\
\hline Vitamin $B_{12}(\mu \mathrm{g} / \mathrm{d})$ & $5 \cdot 9$ & $1 \cdot 6$ & $6 \cdot 6$ & $6 \cdot 7$ & $0 \cdot 1$ & $6 \cdot 7$ & $5 \cdot 3$ & $1 \cdot 8$ & $5 \cdot 0$ & $8 \cdot 5^{\star \star \star}$ & 0.000 \\
\hline Ascorbic acid $(\mathrm{mg} / \mathrm{d})$ & $100 \cdot 3$ & $36 \cdot 8$ & $94 \cdot 7$ & $88 \cdot 9$ & $34 \cdot 3$ & $84 \cdot 1$ & $108 \cdot 1$ & $36 \cdot 5$ & $99 \cdot 0$ & $4 \cdot 6^{\star \star \star}$ & 0.000 \\
\hline \multicolumn{12}{|l|}{ Fat-soluble vitamins } \\
\hline Vitamin A $(\mu \mathrm{g} \mathrm{RE} / \mathrm{d})$ & $833 \cdot 6$ & $165 \cdot 9$ & $823 \cdot 2$ & $800 \cdot 1$ & $137 \cdot 8$ & $802 \cdot 6$ & $856 \cdot 1$ & $179 \cdot 4$ & $844 \cdot 6$ & $2 \cdot 5^{\star}$ & 0.012 \\
\hline Vitamin $\mathrm{K}(\mu \mathrm{g} / \mathrm{d})$ & $134 \cdot 6$ & $30 \cdot 8$ & $132 \cdot 1$ & $142 \cdot 4$ & $32 \cdot 9$ & $139 \cdot 3$ & $129 \cdot 3$ & $28 \cdot 2$ & $125 \cdot 8$ & $3 \cdot 4^{\star \star}$ & 0.001 \\
\hline \multicolumn{12}{|l|}{ Trace elements and minerals } \\
\hline lodine $(\mu \mathrm{g} / \mathrm{d})$ & $59 \cdot 6$ & $13 \cdot 2$ & $57 \cdot 5$ & $60 \cdot 0$ & $12 \cdot 9$ & $57 \cdot 5$ & $59 \cdot 3$ & $13 \cdot 5$ & $57 \cdot 5$ & $0.5^{\mathrm{NS}}$ & 0.613 \\
\hline $\mathrm{Fe}(\mathrm{mg} / \mathrm{d})$ & $15 \cdot 0$ & $2 \cdot 9$ & $14 \cdot 7$ & $16 \cdot 5$ & $2 \cdot 7$ & $16 \cdot 5$ & $14 \cdot 0$ & $2 \cdot 5$ & $13 \cdot 6$ & $7 \cdot 4^{\star \star *}$ & 0.000 \\
\hline $\mathrm{Ca}(\mathrm{mg} / \mathrm{d})$ & $650 \cdot 8$ & $170 \cdot 2$ & $611 \cdot 6$ & $678 \cdot 5$ & $191 \cdot 7$ & $630 \cdot 1$ & $632 \cdot 1$ & $151 \cdot 8$ & $604 \cdot 5$ & $1 \cdot 7^{\mathrm{NS}}$ & 0.076 \\
\hline$M g(m g / d)$ & $266 \cdot 9$ & $47 \cdot 2$ & $262 \cdot 4$ & $284 \cdot 7$ & $38 \cdot 4$ & 283.5 & $255 \cdot 0$ & $48 \cdot 8$ & $251 \cdot 1$ & $5 \cdot 5^{\star \star \star}$ & 0.000 \\
\hline$P(\mathrm{mg} / \mathrm{d})$ & $968 \cdot 9$ & $187 \cdot 5$ & $960 \cdot 1$ & $1036 \cdot 8$ & $164 \cdot 5$ & $1015 \cdot 4$ & $923 \cdot 2$ & $188 \cdot 7$ & $911 \cdot 2$ & $5 \cdot 2^{\star \star \star}$ & 0.000 \\
\hline $\mathrm{K}(\mathrm{mg} / \mathrm{d})$ & $2512 \cdot 0$ & $429 \cdot 8$ & $2497 \cdot 0$ & $2595 \cdot 5$ & $314 \cdot 5$ & $2582 \cdot 7$ & $2455 \cdot 7$ & $485 \cdot 4$ & $2354 \cdot 2$ & $3 \cdot 4^{\star *}$ & 0.001 \\
\hline $\mathrm{Na}(\mathrm{mg} / \mathrm{d})$ & $2580 \cdot 0$ & $586 \cdot 1$ & $2485 \cdot 3$ & $2847 \cdot 7$ & $578 \cdot 3$ & $2784 \cdot 1$ & $2399 \cdot 4$ & $519 \cdot 8$ & $2276 \cdot 3$ & $6 \cdot 5^{\star \star \star}$ & 0.000 \\
\hline
\end{tabular}

$Z$, value of the Mann-Whitney $U$ test; $P, P$ value for Mann-Whitney $U$ test; NE, niacin equivalents; DFE, dietary folate equivalents; RE, retinol equivalents. ${ }^{\star} P<0.05,{ }^{\star \star} P<0.01,{ }^{* \star \star} P<0.001$. 
Table 2 Daily mean nutrient density for vitamins and minerals by sex in Moroccan pupils aged 15-19 years, November 2007-January 2008

\begin{tabular}{|c|c|c|c|c|c|}
\hline & \multicolumn{2}{|c|}{ Boys ( $n$ 118) } & \multicolumn{2}{|c|}{ Girls (n 175) } & \multirow[b]{2}{*}{$P$} \\
\hline & Mean & SD & Mean & SD & \\
\hline \multicolumn{6}{|l|}{ Water-soluble vitamins } \\
\hline Thiamin (mg/MJ) & $0 \cdot 1$ & $0 \cdot 0$ & $0 \cdot 1$ & $0 \cdot 0$ & 0.129 \\
\hline Riboflavin (mg/MJ) & $0 \cdot 1$ & $0 \cdot 0$ & $0 \cdot 2$ & $0 \cdot 0$ & 0.208 \\
\hline Niacin (NE/MJ) & $2 \cdot 7$ & $0 \cdot 3$ & $2 \cdot 6$ & $0 \cdot 3$ & $0 \cdot 311$ \\
\hline Pantothenic acid (mg/MJ) & 0.49 & $0 \cdot 1$ & 0.52 & $0 \cdot 1$ & 0.011 \\
\hline Pyridoxine (mg/MJ) & $0 \cdot 17$ & $0 \cdot 0$ & $0 \cdot 18$ & $0 \cdot 0$ & 0.000 \\
\hline Biotin $(\mu \mathrm{g} / \mathrm{MJ})$ & $2 \cdot 2$ & $0 \cdot 6$ & 2.5 & $0 \cdot 7$ & 0.000 \\
\hline Folate ( $\mu \mathrm{g}$ DFE/MJ) & $30 \cdot 4$ & $4 \cdot 9$ & $29 \cdot 4$ & $4 \cdot 8$ & 0.000 \\
\hline Vitamin $B_{12}(\mu \mathrm{g} / \mathrm{MJ})$ & $0 \cdot 8$ & $0 \cdot 1$ & 0.7 & $0 \cdot 2$ & 0.017 \\
\hline Ascorbic acid (mg/MJ) & $10 \cdot 0$ & $3 \cdot 6$ & $13 \cdot 6$ & $4 \cdot \overline{4}$ & 0.000 \\
\hline \multicolumn{6}{|l|}{ Fat-soluble vitamins } \\
\hline Vitamin A ( $\mu \mathrm{g}$ RE/MJ) & $91 \cdot 3$ & $18 \cdot 7$ & $108 \cdot 0$ & $24 \cdot 0$ & 0.004 \\
\hline Vitamin $\mathrm{K}(\mu \mathrm{g} / \mathrm{MJ})$ & $16 \cdot 2$ & $3 \cdot 7$ & $16 \cdot 3$ & $3 \cdot 3$ & 0.017 \\
\hline \multicolumn{6}{|l|}{ Trace elements and minerals } \\
\hline lodine $(\mu \mathrm{g} / \mathrm{MJ})$ & $6 \cdot 8$ & $1 \cdot 2$ & $7 \cdot 4$ & $1 \cdot 2$ & 0.042 \\
\hline $\mathrm{Fe}(\mathrm{mg} / \mathrm{MJ})$ & 1.9 & $0 \cdot 3$ & $1 \cdot 8$ & 0.2 & 0.002 \\
\hline $\mathrm{Ca}(\mathrm{mg} / \mathrm{MJ})$ & $75 \cdot 9$ & $17 \cdot 2$ & $78 \cdot 7$ & $14 \cdot \overline{5}$ & 0.000 \\
\hline $\mathrm{Mg}(\mathrm{mg} / \mathrm{MJ})$ & $32 \cdot 2$ & $3 \cdot 3$ & $31 \cdot 7$ & $3 \cdot 7$ & 0.000 \\
\hline $\mathrm{P}(\mathrm{mg} / \mathrm{MJ})$ & $117 \cdot 1$ & $14 \cdot 6$ & $114 \cdot 8$ & $15 \cdot 0$ & 0.065 \\
\hline $\mathrm{K}(\mathrm{mg} / \mathrm{MJ})$ & $294 \cdot 4$ & $34 \cdot 7$ & $306 \cdot 7$ & $44 \cdot 3$ & 0.000 \\
\hline $\mathrm{Na}(\mathrm{mg} / \mathrm{MJ})$ & $320 \cdot 3$ & $47 \cdot 9$ & $298 \cdot 8$ & $45 \cdot 6$ & 0.821 \\
\hline
\end{tabular}

$P, P$ value for Mann-Whitney $U$ test $(P>0.05$ indicates that Mann-Whitney $U$ test is not significant); NE, niacin equivalents; DFE, dietary folate equivalents; $\mathrm{RE}$, retinol equivalents.

Table 3 Prevalence of inadequate intakes by nutrient and sex in Moroccan pupils aged 15-19 years, November 2007-January 2008

\begin{tabular}{|c|c|c|c|c|c|c|c|c|}
\hline & \multicolumn{3}{|c|}{ Boys ( $n$ 118) } & \multicolumn{3}{|c|}{ Girls ( $n$ 175) } & \multicolumn{2}{|c|}{ Total (n 293) } \\
\hline & EAR & Prevalence (\%) & $95 \% \mathrm{Cl}$ & EAR & Prevalence (\%) & $95 \% \mathrm{Cl}$ & Prevalence (\%) & $95 \% \mathrm{Cl}$ \\
\hline \multicolumn{9}{|l|}{ Water-soluble vitamins } \\
\hline Thiamint $(\mathrm{mg} / \mathrm{d})$ & 0.92 & $66 \cdot 9$ & $61 \cdot 5,72 \cdot 3$ & 0.85 & $54 \cdot 3$ & $48 \cdot 6,60 \cdot 0$ & $59 \cdot 4$ & $53 \cdot 6,65 \cdot 2$ \\
\hline Riboflavint (mg/d) & $0 \cdot 85$ & $28 \cdot 0$ & $22 \cdot 9,33 \cdot 1$ & $0 \cdot 77$ & $3 \cdot 4$ & $1 \cdot 3,5 \cdot 5$ & $13 \cdot 3$ & $9 \cdot 3,17 \cdot 4$ \\
\hline Niacint (NE/d) & $12 \cdot 3$ & $0 \cdot 0$ & $0.0,0.0$ & $12 \cdot 3$ & $0 \cdot 6$ & $0.3,1.5$ & $0 \cdot 3$ & $0 \cdot 5,1 \cdot 2$ \\
\hline Pantothenic acid $¥(\mathrm{mg} / \mathrm{d})$ & $5 \|$ & $78 \cdot 0$ & $69 \cdot 7,84 \cdot 5$ & 5 & $85 \cdot 1$ & $79 \cdot 1,89 \cdot 6$ & $82 \cdot 3$ & $77 \cdot 5,86 \cdot 2$ \\
\hline Pyridoxinet (mg/d) & $1 \cdot 08$ & $0 \cdot 0$ & $0 \cdot 0,0 \cdot 0$ & $1 \cdot 0$ & $1 \cdot 7$ & $0 \cdot 2,3 \cdot 2$ & $1 \cdot 0$ & $0 \cdot 3,2 \cdot 3$ \\
\hline Biotin $\neq(\mu \mathrm{g} / \mathrm{d})$ & 25 & $83 \cdot 1$ & $75 \cdot 3,88 \cdot 8$ & 25 & $79 \cdot 4$ & $72 \cdot 8,84 \cdot 7$ & $80 \cdot 9$ & $76 \cdot 0,85 \cdot 0$ \\
\hline Folatet $(\mu \mathrm{g}$ DFE/d) & 320 & $74 \cdot 6$ & $69 \cdot 6,79 \cdot 6$ & 320 & $93 \cdot 1$ & $90 \cdot 2,96 \cdot 0$ & $85 \cdot 7$ & $81 \cdot 5,89 \cdot 8$ \\
\hline Vitamin $\mathrm{B}_{12}{ }^{\dagger}(\mu \mathrm{g} / \mathrm{d})$ & $2 \cdot 4$ & 0.0 & $0 \cdot 0,0 \cdot 0$ & $2 \cdot 4$ & 0.0 & $0.0,0.0$ & $0 \cdot 0$ & $0.2,0.2$ \\
\hline Ascorbic acidt (mg/d) & 35 & $0 \cdot 8$ & $0 \cdot 2,1 \cdot 8$ & 35 & $0 \cdot 0$ & $0 \cdot 0,0 \cdot 0$ & $0 \cdot 3$ & $0.5,1.2$ \\
\hline \multicolumn{9}{|l|}{ Fat-soluble vitamins } \\
\hline Vitamin At ( $\mu \mathrm{g} R E / d)$ & 462 & $0 \cdot 8$ & $0 \cdot 2,1 \cdot 8$ & 462 & 0.6 & $0.3,1.5$ & $0 \cdot 7$ & $0 \cdot 4,1 \cdot 8$ \\
\hline Vitamin $\mathrm{K} \dagger(\mu \mathrm{g} / \mathrm{d})$ & 45 & $0 \cdot 0$ & $0 \cdot 0,0 \cdot 0$ & 40 & $0 \cdot 0$ & $0.0,0.0$ & $0 \cdot 0$ & $0 \cdot 4,1 \cdot 8$ \\
\hline \multicolumn{9}{|l|}{ Trace elements and minerals } \\
\hline lodinet $(\mu \mathrm{g} / \mathrm{d})$ & 90 & 94.9 & $92 \cdot 4,97 \cdot 4$ & 80 & $88 \cdot 0$ & $84 \cdot 3,91 \cdot 7$ & $90 \cdot 8$ & $87 \cdot 3,94 \cdot 3$ \\
\hline $\mathrm{Fe} \S(\mathrm{mg} / \mathrm{d})$ & 12 & 0.0 & $0.0,0.0$ & 15 & $17 \cdot 7$ & $13 \cdot 3,22 \cdot 1$ & $10 \cdot 6$ & $6 \cdot 9,14 \cdot 3$ \\
\hline $\mathrm{Cat}(\mathrm{mg} / \mathrm{d})$ & 924 & $74 \cdot 6$ & $69 \cdot 6,79 \cdot 6$ & 924 & $83 \cdot 4$ & $79 \cdot 1,87 \cdot 7$ & $79 \cdot 9$ & $75 \cdot 1,84 \cdot 7$ \\
\hline $\mathrm{Mg}+(\mathrm{mg} / \mathrm{d})$ & 215 & $1 \cdot 7$ & $0 \cdot 2,3 \cdot 2$ & 207 & $8 \cdot 0$ & $4 \cdot 9,11 \cdot 1$ & $5 \cdot 5$ & $2 \cdot 7,8 \cdot 3$ \\
\hline $\mathrm{Pt}(\mathrm{mg} / \mathrm{d})$ & 962 & $28 \cdot 0$ & $22 \cdot 9,33 \cdot 1$ & 962 & $56 \cdot 0$ & $50 \cdot 3,61 \cdot 7$ & $44 \cdot 7$ & $38 \cdot 8,50 \cdot 6$ \\
\hline Nall (mg/d) & 1500 & 100 & $99 \cdot 6,100 \cdot 4$ & 1500 & $97 \cdot 7$ & $94 \cdot 2,99 \cdot 8$ & $98 \cdot 1$ & $96 \cdot 4,99 \cdot 8$ \\
\hline $\mathrm{K} \ddagger(\mathrm{mg} / \mathrm{d})$ & $4700^{\circ}$ & 100 & $99 \cdot 6,100 \cdot 4$ & $4700^{\circ}$ & 100 & $97 \cdot 9,100 \cdot 0$ & 100 & $98 \cdot 7,100 \cdot 0$ \\
\hline
\end{tabular}

EAR, Estimated Average Requirement; NE, niacin equivalents; DFE, dietary folate equivalents; RE, retinol equivalents; Al, Adequate Intake. tProportion of individuals with intake below the EAR

†Proportion of individuals with intake below the Al.

SPrevalence of inadequate intake by the probability approach.

IIProportion of individuals with intake above the Al.

๑Al.

\section{Prevalence of inadequate nutrient intakes}

Table 3 shows the prevalence of inadequate nutrient intakes for the total sample and by sex. Overall, the adolescents were identified as being at risk of inadequacy for folate, pantothenic acid, biotin, iodine, $\mathrm{Ca}$ and $\mathrm{K}$. Boys were also particularly at risk of inadequacy for thiamin $(66.9 \%)$ and girls had a very high risk of inadequacy for folate $(93 \cdot 1 \%)$. The prevalence of inadequacy for other nutrients was low (5- $45 \%$ for riboflavin, $\mathrm{Fe}, \mathrm{Mg}$ and $\mathrm{P}$ ) to negligible ( $\leq 1 \%$ for niacin, pyridoxine, ascorbic acid, vitamins $\mathrm{B}_{12}$, $\mathrm{A}$ and $\mathrm{K}$ ).

For the total sample, the median usual intakes of $\mathrm{Ca}$ were below adequate levels. Similarly, the median usual 
Table 4 Percentage contribution of food groups to micronutrient intakes (thiamin, folate, calcium and sodium) by sex in Moroccan pupils aged 15-19 years, November 2007-January 2008

\begin{tabular}{|c|c|c|c|c|c|c|c|c|c|c|c|c|}
\hline & \multicolumn{12}{|c|}{ Micronutrient } \\
\hline & \multicolumn{3}{|c|}{ Thiamin } & \multicolumn{3}{|c|}{ Folate } & \multicolumn{3}{|c|}{$\mathrm{Ca}$} & \multicolumn{3}{|c|}{$\mathrm{Na}$} \\
\hline & Boys & Girls & & Boys & Girls & & Boys & Girls & & Boys & Girls & \\
\hline & $\%$ & $\%$ & $P$ & $\%$ & $\%$ & $P$ & $\%$ & $\%$ & $P$ & $\%$ & $\%$ & $P$ \\
\hline \multicolumn{13}{|l|}{ Food group } \\
\hline Cereals and cereal products & $40 \cdot 7$ & $36 \cdot 9$ & 0.001 & $34 \cdot 0$ & $30 \cdot 6$ & 0.002 & $28 \cdot 8$ & $22 \cdot 6$ & 0.000 & $54 \cdot 7$ & $45 \cdot 0$ & 0.000 \\
\hline Legumes & $9 \cdot 6$ & $5 \cdot 5$ & 0.002 & $15 \cdot 0$ & $8 \cdot 2$ & 0.001 & $3 \cdot 2$ & $1 \cdot 5$ & 0.000 & $0 \cdot 1$ & $0 \cdot 1$ & 0.099 \\
\hline Vegetables & $15 \cdot 1$ & $16 \cdot 8$ & $0 \cdot 018$ & $17 \cdot 1$ & $20 \cdot 4$ & 0.000 & $4 \cdot 4$ & $4 \cdot 9$ & 0.054 & $1 \cdot 2$ & $1 \cdot 4$ & 0.098 \\
\hline Fruit & $12 \cdot 9$ & $16 \cdot 4$ & 0.001 & $15 \cdot 6$ & $21 \cdot 6$ & 0.000 & $7 \cdot 5$ & $9 \cdot 9$ & 0.001 & 0.5 & 0.5 & 0.754 \\
\hline Milk and milk products & $8 \cdot 2$ & $9 \cdot 6$ & $0 \cdot 114$ & $4 \cdot 2$ & $4 \cdot 8$ & $0 \cdot 149$ & $31 \cdot 5$ & $39 \cdot 5$ & 0.001 & $5 \cdot 6$ & $6 \cdot 6$ & 0.092 \\
\hline Meat and meat products & $2 \cdot 9$ & $2 \cdot 7$ & 0.631 & 1.5 & $1 \cdot 5$ & 0.942 & 0.6 & $0 \cdot 6$ & $0 \cdot 752$ & $2 \cdot 8$ & $2 \cdot 3$ & 0.345 \\
\hline Fish & $0 \cdot 8$ & $0 \cdot 7$ & $0 \cdot 713$ & 0.9 & $0 \cdot 7$ & $0 \cdot 155$ & $3 \cdot 6$ & $2 \cdot 0$ & 0.026 & $1 \cdot 5$ & $1 \cdot 1$ & $0 \cdot 122$ \\
\hline Eggs & $2 \cdot 6$ & $2 \cdot 7$ & $0 \cdot 769$ & $4 \cdot 3$ & $4 \cdot 6$ & 0.540 & $1 \cdot 9$ & $2 \cdot 0$ & $0 \cdot 819$ & $1 \cdot 1$ & $1 \cdot 2$ & 0.287 \\
\hline Sugar, preserves and confectionery & $0 \cdot 3$ & 0.5 & 0.018 & $0 \cdot 2$ & 0.5 & 0.067 & $0 \cdot 6$ & $1 \cdot 0$ & 0.035 & 0.3 & $0 \cdot 4$ & 0.291 \\
\hline Oils and fats & $0 \cdot 0$ & $0 \cdot 0$ & 0.030 & $0 \cdot 0$ & $0 \cdot 0$ & 0.007 & 0.2 & $0 \cdot 3$ & 0.001 & $2 \cdot 1$ & $3 \cdot 4$ & 0.000 \\
\hline Beverages & $1 \cdot 2$ & $1 \cdot 3$ & $0 \cdot 786$ & $1 \cdot 0$ & 0.9 & $0 \cdot 705$ & $10 \cdot 7$ & $9 \cdot 1$ & 0.038 & 0.3 & $0 \cdot 3$ & 0.933 \\
\hline Spices and condiments & $5 \cdot 6$ & $6 \cdot 7$ & $0 \cdot 118$ & $6 \cdot 0$ & $6 \cdot 0$ & 0.839 & $7 \cdot 3$ & $6 \cdot 8$ & 0.255 & $29 \cdot 7$ & $37 \cdot 5$ & 0.000 \\
\hline
\end{tabular}

$P, P$ value for Pearson's $\chi^{2}$ test.

intakes for K were below the AI level of $4700 \mathrm{mg} / \mathrm{d}$. On the other hand, $\mathrm{Na}$ intakes were well above the AI of $1500 \mathrm{mg} / \mathrm{d}$.

\section{Contribution of twelve food groups to mean micronutrient intakes}

The contribution of twelve food groups to mean micronutrient intakes (thiamin, folate, $\mathrm{Ca}$ and $\mathrm{Na}$ ) is shown in Table 4. We did not look at intakes of $\mathrm{K}$, pantothenic acid or biotin in this analysis since they were not generated by the DIAL program. Cereals and cereal products represented the principal source of thiamin, contributing about $38 \%$ of daily intake, followed by the vegetable/legume group and fruit which contributed about $23 \%$ and $15 \%$, respectively. Vegetables and legumes constituted, together with cereal products, the main sources of folate, contributing respectively $32 \%$ and $31 \%$, with fruit contributing $19 \%$. On the other hand, the contribution of spices, milk products and eggs to daily folate intake was negligible, about 4 to $6 \%$. Milk products (36\%) represented the principal source of $\mathrm{Ca}$ followed by cereal products $(23 \%)$. The contribution of other food groups to Ca intake was considerably lower, from 0.6 to $9.9 \%$. The main sources of $\mathrm{Na}$ were cereal products and spices. Milk products also made a small contribution to $\mathrm{Na}$ intake, of about 5 to $6 \%$. The $\mathrm{Na}$ contribution of other food groups was negligible, ranging from $0 \cdot 1$ to $5 \cdot 6 \%$.

The differences between boys and girls in the contribution of the food groups to micronutrient intakes are also seen in Table 4. The percentage contribution of cereals and cereal products was consistently higher in boys for all four micronutrients. For thiamin and folate, legumes were a more important source in boys than in girls, for whom fruit and vegetables were more important. In girls, milk products, fruit, sugar/confectionery and oils were more important sources of Ca intake than in boys, in whom legumes, fish and beverages made a higher contribution to total $\mathrm{Ca}$ intake than in girls. As for $\mathrm{Na}$, spices and condiments made a greater contribution in girls than in boys.

\section{Discussion}

The present study has enabled us to identify several areas for concern and provides a basis for further, larger studies of dietary behaviour in Moroccan teenagers. We found significant differences between boys and girls in the median usual intakes and nutrient densities of certain vitamins and minerals. The adolescents were identified as being particularly at risk of inadequate intake of folate, pantothenic acid, biotin, iodine, Ca and K. Boys had an additional risk of inadequate thiamin intake. Excessive $\mathrm{Na}$ intake was observed in both sexes.

Since our study excluded adolescents not attending school, our sample is not representative of the total adolescent population in the region or elsewhere in Morocco. However, there are no available data that allow us to determine just how representative our sample is and in what way, if any, it differs from the total adolescent population. Compared with other urbanised parts of Morocco, the adolescents of the Ouarzazate area are less influenced by Western practices, rarely eat fast food and have less pocket money for purchasing food outside the home.

The 327 adolescents in the final study sample represent $7 \cdot 1 \%$ of the target population, but $35 \cdot 5 \%$ of the adolescents actually volunteering to participate. Participation was purely voluntary, and no means of persuasion, coercion or reward were used. Given the logistic difficulties and the nature of the research, we feel that this response rate is satisfactory. 
We chose to use the prospective $3 \mathrm{~d}$ food consumption logbook, a compromise between the week-long record and single day recall, with estimation of quantities using common household measures ${ }^{(33,34)}$ rather than weighing, since this method provides acceptably accurate qualitative and quantitative data while avoiding the risks of recall error ${ }^{(35)}$ and loss of motivation, and seems to offer the best results in a young population ${ }^{(36)}$. It should be noted that the results have not been validated by objective biological measures such as blood or urine tests.

Our study used the DIAL program to estimate nutrient intakes. This software has amalgamated several food composition tables, including Spanish tables ${ }^{(16,17)}$ and those of the US Department of Agriculture ${ }^{(18)}$. Although this database has been adapted for Moroccan foods ${ }^{(19)}$, there may be some inaccuracies due to a lack of current nutritional information for certain foods, in particular those most typical of the country ${ }^{(37)}$. However, regional variations in nutrient content are diminishing as the food products from different parts of the world are becoming more widely available. There is nevertheless an urgent need for further research on dietary practices in the Moroccan population, to enable the updating of Moroccan food composition databases.

In Morocco, there are few published studies of the prevalence of inadequate nutrient intakes ${ }^{(38)}$, particularly in adolescents, nor do any national dietary recommendations exist for this age group. For this reason, we have relied on the recommendations published by the US Institute of Medicine.

Boys had higher absolute intakes than girls for most vitamins and minerals, except for riboflavin, biotin and iodine (which were identical) and ascorbic acid and vitamin A (which were higher in girls). In terms of nutrient densities, girls had better-quality diets than boys, with values higher than or equal to those of boys except for folate, vitamin $\mathrm{B}_{12}, \mathrm{Fe}$ and $\mathrm{Mg}$. These results are consistent with the findings of studies in non-Moroccan populations ${ }^{(39-43)}$.

Although comparisons are limited due to differences in methodology and the variables studied, it is interesting here to consider the results of a 2005 study of adolescents in Tunisia, a North African country with certain similarities to Morocco ${ }^{(43)}$. Although not exactly identical, the same type of North African Mediterranean diet, distinguished from the West Mediterranean diet by its higher consumption of cereals and little meat or dairy foods, is followed in Tunisia and Morocco ${ }^{(44,45)}$. Traditionally wheat-consuming countries, Morocco has a more diversified cereal mix than Tunisia, with relatively high levels of barley and some maize ${ }^{(46)}$.

Using a semi-quantitative frequency questionnaire (SFFQ), the Tunisian study found energy intake levels that were relatively high, especially for girls, unlike our own findings. However, there is some evidence that the SFFQ overestimates average absolute nutrient intakes ${ }^{(47)}$.
On the basis of nutrient densities, boys had lower values for ascorbic acid than girls, as in our sample, but only the nutrient density for Ca was higher in boys. The authors conclude that modernisation, urbanisation and regional development have led to dietary changes with both positive and negative effects: a more varied, adequate diet on the one hand, but excess intakes of energy and fat on the other. The nutrition transition in adolescents is certainly a subject that demands more attention in Morocco, since this age group is perhaps the most exposed and vulnerable to the influences of globalisation.

The differences in micronutrient intake between girls and boys may be explained in part by sex-specific quantitative and qualitative differences in the usual diets. Other analyses of our data have shown that boys consumed higher quantities of energy, protein and carbohydrate than girls, but no differences were observed for lipids and cholesterol ${ }^{(5)}$. The boys in our sample ate larger portions than girls, except for foods containing ascorbic acid and vitamin A (boys ate smaller portions or less varied foods) and iodine-rich foods (equal portions).

The risk of inadequate folate intake might be explained by infrequent or limited consumption of foods naturally rich in folate, of either plant origin (lentils, dried beans) or animal origin (offal). Similar findings have been reported in the Canadian Community Health Survey ${ }^{(32)}$, in which it was recommended that girls aged 14-18 years be monitored for folate in particular, since about $9 \%$ of this group did not satisfy their needs for this nutrient. Folate intake may be improved by adding folate to flour and pasta. Since 2001, flour in Morocco has been fortified with folate and a project to fortify flour with $\mathrm{Fe}$, folate, thiamin, riboflavin and niacin and vegetable oil with vitamins $\mathrm{A}$ and D was launched in $2005^{(48)}$. Flour was chosen as the vehicle since it is widely consumed in the Moroccan population $^{(46)}$.

Cereals and legumes are an important source of thiamin. In our sample, the contribution of cereals ( $40 \cdot 7 \%)$ and legumes $(9.6 \%)$ to thiamin intake in boys was higher than in girls (36.9\% and 5.5\%, respectively) and boys ate larger quantities of these foods than girls. Boys had a higher absolute intake of thiamin but there were no differences between boys and girls in thiamin nutrient density. However, the risk of inadequate thiamin intake was seen only in boys. Since it is unlikely that thiamin intake has been underestimated in boys alone, which might be the case if other sources of thiamin not taken into account were available to boys but not to girls, our findings suggest that boys need to eat more thiamin-rich foods to meet their higher requirements.

Inadequacies of two other B-group vitamins, pantothenic acid and biotin, were observed in both sexes. The sources of pantothenic acid (vitamin $\mathrm{B}_{5}$ ) are abundant and include animal tissues, wholegrain cereals and legumes. Biotin (vitamin $\mathrm{B}_{8}$ ) is found in liver, yeast, eggs and cereals. In other words, there is some overlap with 
sources of folate and thiamin, which were also lacking in our participants' diets. Given the ubiquitous nature of pantothenic acid, clinical deficiencies - manifest by headache, fatigue, insomnia, intestinal disturbances, and numbness and tingling of the hands and feet - are exceptionally rare. Questioning for symptoms of nutritional deficiencies and clinical or biological examination were beyond the scope of the present study. Ideally, future nutrition research should also investigate the physiological and clinical aspects of dietary inadequacy.

The median usual intake of Ca was below the adequate level, indicating a fairly high risk of inadequate intake that deserves attention. This finding can be explained by dietary habits that favour the national beverage (mint tea) over milk-based drinks. Nevertheless, dairy products such as whey and yoghurt are part of the traditional Moroccan diet and need to be promoted.

The infrequent consumption of fish and intra-group variability in the geographical area of the study ${ }^{(49)}$ can explain the high risk of inadequate iodine intake. Concerning the validity of our figures, it should be noted that, given the wide variation of the iodine content of food with geographic location according to the iodine content of environmental media ${ }^{(50)}$, the average iodine content of foods used in the DIAL program cannot be used universally for estimating iodine intake. Iodine deficiency is an important cause of preventable cognitive impairment in children. The WHO Global Database on Iodine Deficiency, 2006 update $^{(51)}$, reports a total goitre prevalence of $46.9 \%$ in children aged $6-13$ years ( $n$ 32) for the Ouarzazate Province, the region of our study.

A question on iodised salt use was included in a nutritional questionnaire, as part of a Moroccan child and maternal health project ${ }^{(52)}$. It was found that only fourfifths of urban households used iodised salt in food preparation. To compound the problem, the salt industry in Morocco is poorly organised, most producers are too poor to support the cost of iodising their salt, and the salt iodisation programme has never been effectively promoted to consumers ${ }^{(53)}$. There is thus a need to encourage better compliance on the part of industrial players. Other potential food vehicles for iodine fortification might also be considered.

$\mathrm{Na}$ and $\mathrm{K}$ balance is important for maintaining normal blood pressure. $\mathrm{K}$ is found in a wide variety of unprocessed foods, fruit and vegetables in particular, and is often lacking in diets low in fruit and vegetables ${ }^{(54)}$. This appears to be the case for the adolescent population studied here. Recent WHO guidelines recommend an increase in $\mathrm{K}$ intake in children and adolescents to control the risk of hypertension ${ }^{(54)}$. There is a potential risk of underestimating $\mathrm{K}$ intake in the present study. The DIAL program did not allow us to determine the contribution of food groups to $\mathrm{K}$ intake.

In our sample, over $60 \%$ of adolescents had intakes above the tolerable upper level for $\mathrm{Na}$ whereas $\mathrm{K}$ intake was below the AI. This imbalance has been observed in teenagers ( 13 years and older) in Portugal ${ }^{(55)}$, which has a high prevalence of adolescent hypertension $(22 \%)^{(56)}$. However, the inability to account precisely for added salt and the fact that much salt is discarded with cooking water in many highly spiced Moroccan dishes, incurring a risk of overestimating actual consumption, should be taken into consideration.

The low risk of Fe inadequacy we observed should not be cause for complacency, since Fe deficiency is an important problem in the Moroccan population ${ }^{(57,58)}$. The WHO Global Database on Anaemia, 2008 update $^{(59)}$, reports a total anaemia prevalence of $32 \cdot 6 \%$ in a national sample of non-pregnant women aged $15-49$ years ( $n$ 1784). Among the major causes of anaemia are dietary Fe deficiency and deficiencies of other key micronutrients including folate, vitamin $\mathrm{B}_{12}$ and vitamin $\mathrm{A}$. Total Fe intake was high and total $\mathrm{Fe}$ adequacy was $100 \%$ in boys and $82.3 \%$ in girls. However, we must consider that the reference used for the probability approach or EAR (based on the diet of the US population) assumes a high bioavailability of $18 \%$, which may be above that found in Morocco. Ideally, the Fe status of adolescents should be assessed and monitored by appropriate biological indicators such as $\mathrm{Hb}^{(60)}$.

The different food groups contributed unequally to the intakes of the four micronutrients studied. Despite an overall downward trend in consumption, cereal products continue to occupy an important place in the Moroccan diet $^{(61)}$ and made the highest contribution to the intakes of all micronutrients except $\mathrm{Ca}$. Cereal products are used in the preparation of many dishes and form the basis of daily meals consumed by households, particularly in rural areas $^{(46)}$. As expected, milk and milk products were the highest contributors to $\mathrm{Ca}$ intake in our sample $(36 \cdot 2 \%)$.

Our survey revealed that the micronutrient contribution from spices ranged from 5.7 to $6.5 \%$ for folate, thiamin and $\mathrm{Ca}$, but $33.0 \%$ for $\mathrm{Na}$. In our study area, the typical spices of the highly spiced Moroccan cuisine (cumin, black pepper, ginger, garlic, sweet pepper, cinnamon, saffron and pepper) are widely consumed ${ }^{(49)}$. Most herbs and spices contain the B-complex vitamins and minerals like $\mathrm{Fe}$ and $\mathrm{Ca}$ in appreciable concentrations ${ }^{(62,63)}$. However the quantities eaten are too small to make a significant contribution to intake.

Certain dietary practices are known to be seasonal. This is certainly the case for fresh fruits and vegetables, which are eaten less often in winter, when starchy foods are eaten more frequently. As our study took place in winter, seasonal factors may partly explain the differences observed between intakes and dietary recommendations.

\section{Conclusion}

We feel that interventions are necessary to address the risk of folate, thiamin, pantothenic acid, biotin, iodine, 
$\mathrm{Ca}$ and $\mathrm{K}$ deficiency and of excess $\mathrm{Na}$ intake in this adolescent population. Such actions should include health education activities aimed at young people to encourage healthy eating; the promotion of the traditional Moroccan diet rich in cereals, legumes and dairy products; the fortification of foods with folate and iodine; and more extensive research on the dietary practices and nutritional status of the Moroccan population. We recommend the creation of a national body to address nutritional issues and the urgent updating of Moroccan food composition tables. Given the lack of previous Moroccan studies of adolescents, it is difficult to determine whether or not the observed inadequacies are a recent phenomenon related to the transition to a more Westernised diet. Clinical and biological assessment of the nutritional status of adolescents focusing on the micronutrients of concern would seem advisable.

\section{Acknowledgements}

Sources of funding: This study benefited from financial assistance from the Semlalia Science Faculty of Cadi Ayyad University, Marrakech and the project 'Transición Alimentaria en las Poblaciones y su Impacto en la Biología y la Salud' funded by the Spanish Agency for International Development Cooperation (AECID; ref. A/016317/08). The funders had no role in the design, analysis or writing of this article. The authors alone are responsible for the content and writing of the paper. Conflicts of interest: The authors report no conflicts of interest. Ethics: The study was conducted in accordance with ethical standards. Authors' contributions: K.A., P.M.L. and M.C. designed the study. K.A. carried out the data collection, analysis and interpretation, and drafted the manuscript. S.L.-D., P.M.L., P.V., A.B. and M.C. contributed to the data interpretation and critical revision of the manuscript. S.L.-D. gave advice on and supervised the English version of the manuscript. Acknowledgements: The authors are grateful to M. Rguibi and L. Lafay for their advice and suggestions. They thank the Regional Academy of Education and Training Souss-Massa-Draa and provincial delegation Ouarzazate, participating high-school pupils, their families and teachers, and administrative staff of the five high schools.

\section{References}

1. Ministry of Public Health, Morocco (2008) Lutte contre les troubles dus aux carences en micronutriments (Control of disorders caused by micronutrient deficiencies) http://srvweb.sante.gov.ma/Publications/Guides-Manuels/ Documents/Lutte contre les troubles[1].pdf (accessed July 2010).

2. Maire B, Lioret S, Gartner A et al. (2002) Transition nutritionnelle et maladies chroniques non transmissibles liées à l'alimentation dans les pays en développement (Nutritional transition and non-communicable diet-related chronic diseases in developing countries). Santé 12, 45-55.
3. Aboussaleh Y, Farsi M, El Hioui M et al. (2009) Nutrition transition in Morocco: coexistence of anemia and obesity in women in North West of Morocco. Antropo 19, 67-74.

4. Popkin BM (2004) The nutrition transition: an overview of world patterns of change. Nutr Rev 62, 7 Pt 2, S140-S143.

5. López PM, Anzid K, Cherkaoui M et al. (2012) Nutritional status of adolescents in the context of the Moroccan nutritional transition: the role of parental education. J Biosoc Sci 44, 481-494.

6. Serra-Majem L, García-Closas R, Ribas L et al. (2001) Food patterns of Spanish schoolchildren and adolescents: the enKid Study. Public Health Nutr 4, 1433-1438.

7. Delisle H, Chandra-Mouli V \& de Benoist B (2005) Should Adolescents Be Specifically Targeted for Nutrition in Developing Countries? To Address Which Problems, And How? Geneva: WHO.

8. Rees JM (1996) Nutrition in adolescence. In Krause's Food, Nutrition and Diet Therapy, 9th ed., pp. 257-270 [LK Mahan and S Escott-Stump, editors]. Philadelphia, PA: WB Saunders.

9. Garn SM \& Wagner B (1969) The adolescent growth of the skeletal mass and its implications to mineral requirements. In Adolescent Nutrition and Growth, pp. 139-161 [FP Heard, editor]. New York: Appleton-Century-Crofts.

10. National Research Council (1989) Recommended Dietary Allowances, 10th ed. Washington, DC: National Academy Press.

11. Rome ES, Vazquez IM \& Blazer NE (2003) Adolescence: healthy and disordered eating. In Nutrition in Pediatrics, 3rd ed., pp. 861-877 [WA Walker, JB Watkins and C Duggan, editors]. London, Ontario: BC Decker Inc.

12. Schneider D (2000) International trends in adolescent nutrition. Soc Sci Med 51, 955-967.

13. Monge-Rojas R (2001) Marginal vitamin and mineral intake of Costa Rican adolescents. Arch Med Res 32, 70-78.

14. Garipagaoglu M, Oner N, Vatansever U et al. (2008) Dietary intakes of adolescents living in Edirne, Turkey. J Am Coll Nutr 27, 394-400.

15. Alce Ingeniería (2004). DIAL Programa de Nutrición. Tablas de composición de alimentos (DIAL Nutrition Program. Food Composition Tables). Madrid: Alce Ingeniería; available at www.alceingenieria.net/nutricion.htm

16. Cervera P (2002) Tablas de composición de alimentos (Food Composition Tables). Barcelona: Edicions de la Universitat de Barcelona.

17. Ortega RM, López-Sobaler AM, Requejo AM et al. (2004) La composición de los alimentos. Herramienta básica para la valoración nutricional (Food Composition. Basic Tool for Nutritional Assessment). Madrid: Editorial Complutense.

18. US Department of Agriculture (2003) Nutrient Database for Standard Reference, Release 12. Beltsville, MD: USDA, Agricultural Research Service; available at http://www. ars.usda.gov/Services/docs.htm?docid $=8964$

19. El Moumni K, Maimouni E \& Dufourny G (2008) Aliments et préparations typiques de la population marocaine (Typical Foods and Dishes of the Moroccan Population). Brussels: CIRIHA; available at http://www.ciriha.org/fr/ publications.html

20. Wu Leung WT (1968) Food Composition Table for Use in Africa. Rome/Bethesda, MD: FAO/US Department of Health, Education, and Welfare; available at http://www. fao.org/docrep/003/X6877E/X6877E00.htm

21. Department of Epidemiology, German Institute of Human Nutrition Potsdam-Rehbrücke (2008) The Multiple Source Method (dife-2008/2009 Version 1•0). https://nugo.dife.de/ $\mathrm{msm} /$ (accessed May 2010).

22. Black AE (2000) Critical evaluation of energy intake using the Goldberg cut-off for energy intake:basal metabolic rate. A practical guide to its calculation, use and limitations. Int $J$ Obes Relat Metab Disord 24, 1119-1130. 
23. Institute of Medicine (2000) DRI Dietary Reference Intakes: Applications in Dietary Assessment. Washington, DC: National Academy Press.

24. Institute of Medicine (1997) Dietary Reference Intakes for Calcium, Phosphorus, Magnesium, Vitamin D, and Fluoride. Washington, DC: National Academy Press.

25. Institute of Medicine (1998) Dietary Reference Intakes: Thiamin, Riboflavin, Niacin, Vitamin $B_{6}$, Folate, Vitamin $B_{12}$, Pantothenic Acid, Biotin, and Choline. Washington, DC: National Academy Press.

26. Institute of Medicine (2001) Dietary Reference Intakes: Vitamin A, Vitamin K, Arsenic, Boron, Chromium, Copper, Iodine, Iron, Manganese, Molybdenum, Nickel, Silicon, Vanadium, and Zinc. Washington, DC: National Academy Press.

27. Institute of Medicine (2000) Dietary Reference Intakes: Vitamin C, Vitamin E, Selenium, and Carotenoids. Washington, DC: National Academy Press.

28. Institute of Medicine (2005) Dietary Reference Intakes for Energy, Carbohydrate, Fibre, Fat, Fatty Acids, Cholesterol, Protein and Amino Acids (Macronutrients). Washington, DC: The National Academies Press.

29. Subcommittee on Criteria for Dietary Evaluation, Coordinating Committee on Evaluation of Food Consumption Surveys, Food and Nutrition Board, National Research Council (1986) Nutrient Adequacy: Assessment Using Food Consumption Surveys. Washington, DC: The National Academies Press.

30. De Lauzon B, Volatier JL \& Martin A (2004) A Monte Carlo simulation to validate the EAR cut-point method for assessing the prevalence of nutrient inadequacy at the population level. Public Health Nutr 7, 893-900.

31. Touvier M, Lioret S, Vanrullen I et al. (2006) Vitamin and mineral inadequacy in the French population: estimation and application for the optimization of food fortification. Int J Vitam Nutr Res 76, 343-351.

32. Health Canada, Statistics Canada (2009) Canadian Community Health Survey, Cycle 2.2, Nutrition (2004) - Nutrient Intakes from Food: Provincial, Regional and National Data Tables Volumes 1, 2 \& 3, Disk. Ottawa: Health Canada.

33. Ministry of Social Affairs, Morocco (1998) Enquête nationale sur les revenus des ménages, la consommation et les dépenses de la population marocaine (National survey of household incomes, consumption and expenditure of the Moroccan population). http://www.hcp.ma/downloads/ Niveau-de-vie-et-pauvrete-Enquete-nationale-sur-les-niveauxde-vie-des-menages_t13111.html (accessed May 2007).

34. Aranceta BJ, Serra-Majem L, Perez-Rodrigo C et al. (2006) Nutrition risk in the child and adolescent population of the Basque country: the enKid Study. Br J Nutr 96, Suppl. 1, S58-S66.

35. Cano N, Barnoud D, Schneider S et al. (2007) Traité de nutrition artificielle de l'adulte. Nourrir l'Homme malade, troisième édition (Treatise on Artificial Nutrition in Adults: Feeding Sick Humans, 3rd ed.). Paris: Springer-Verlag France.

36. Black AE, Prentice AM, Goldberg GR et al. (1993) Measurements of total energy expenditure provide insights into the validity of dietary measurements of energy intake. J Am Diet Assoc 93, 572-579.

37. Collier A, Lemaire B, Essatara MB et al. (1978). Contribution à l'élaboration d'une table de composition alimentaire des aliments au Maroc (Contribution to the development of a food composition table for food in Morocco). Institut Agronomique et Vétérinaire Hassan II, Bloc de Nutrition Humaine et d'Économie Alimentaire, Rabat. http://www. documentation.ird.fr/hor/fdi:03909 (accessed January 2011).

38. Belgnaoui S \& Belahsen R (2006) Nutrient intake and food consumption among pregnant women from an agricultural region of Morocco. Int J Food Sci Nutr 57, 19-27.
39. Lambert J, Agostoni C, Elmadfa I et al. (2004) Dietary intake and nutritional status of children and adolescents in Europe. BrJ Nutr 92, Suppl. 2, S147-S211.

40. Decarli B, Cavadini C, Grin J et al. (2000) Food and nutrient intakes in a group of 11 to 16 year old Swiss teenagers. Int J Vitam Nutr Res 70, 139-147.

41. Mirmiran P, Azadbakht L \& Azizi F (2005) Dietary qualityadherence to the dietary guidelines in Tehranian adolescents: Tehran Lipid and Glucose Study. Int J Vitam Nutr Res 75, 195-200.

42. Monge-Rojas R (2001) Marginal vitamin and mineral intake of Costa Rican adolescents. Arch Med Res 32, 70-78.

43. Aounallah-Skhiri H, Traissac P, El Ati J et al. (2011) Nutrition transition among adolescents of a south-Mediterranean country: dietary patterns, association with socio-economic factors, overweight and blood pressure. A cross-sectional study in Tunisia. Nutr J 10, 38.

44. Noah A \& Truswell AS (2001) There are many Mediterranean diets. Asia Pac J Clin Nutr 10, 2-9.

45. Grigg D (1999) Food consumption in the Mediterranean region. Tijdschr Econ Soc Geogr 90, 391-409.

46. Delisle H (1990) Patterns of Urban Food Consumption in Developing Countries: Perspective from the 1980s. Rome: FAO; available at ftp://ftp.fao.org/es/esn/nutrition/urban/ delisle_paper.pdf

47. Andersen LF, Lande B, Arsky GH et al. (2003) Validation of a semi-quantitative food-frequency questionnaire used among 12-month-old Norwegian infants. Eur J Clin Nutr 57, 881-888.

48. Global Alliance for Improved Nutrition (2012) Morocco Wheat Flour and Vegetable Oil Fortification Project. http://www.gainhealth.org/project/morocco-wheat-flourand-vegetable-oil-fortification-project (accessed September 2012).

49. Anzid K, Elhamdani FZ, Baali A et al. (2009) The effect of socio-economic status and area of residence on household food variety in Morocco. Ann Hum Biol 36, 727-749.

50. Koutras DA, Matovinovic J \& Vought R (1985) The ecology of iodine. In Endemic Goitre and Endemic Cretinism. Iodine Nutrition in Health and Disease, pp. 185-195 [JB Stanbury and BS Hetzel, editors]. New Delhi: Wiley Eastern Limited.

51. WHO Global Database on Iodine Deficiency (2006) Data by country on goitre prevalence and/or urinary iodine concentration. http://who.int/vmnis/iodine/data/database/ countries/mar_idd.pdf (accessed June 2013).

52. Bensaid D, El Akkaoui A \& El Ghordaf A (2005) Analyse de la situation des enfants à Fès, Marrakech et Tanger (Analysis of the Situation of Children in Fez, Marrakesh and Tangier). Rabat: UNICEF Morocco; available at http://www.unicef.org/morocco/french/Situation_des_Enfants. pdf

53. Aguenaou H (2007) La malnutrition invisible ou la «faim cachée» au Maroc et les stratégies de lutte (Invisible malnutrition or 'hidden hunger' in Morocco and control strategies). Biomatec Echo 5, 158-164.

54. World Health Organization (2012) Guideline: Potassium Intake for Adults and Children. Geneva: WHO.

55. Tânia R (2009) Prevalência de ingestão inadequada e seus determinantes em adolescentes do Porto (Prevalence of inadequate dietary intake and its determinants in adolescents in Porto). Master of Public Health Thesis, University of Porto.

56. Ramos E \& Barros H (2005) Prevalence of hypertension in 13-year-old adolescents in Porto, Portugal. Rev Port Cardiol 24, 1075-1087.

57. Ministry of Health, Morocco/World Health Organization (2005) Politique de santé de l'enfant au Maroc: analyse de situation (Child Health Policy in Morocco: Analysis of the Situation). Rabat: Ministry of Health; available 
at http://www.sante.gov.ma/Departements/DP/PDF/SMI/ RapPolitiq.pdf

58. El Hioui M, Ahami AOT, Aboussaleh Y et al. (2008) Risk factors of anaemia among rural schoolchildren in Kenitra, Morocco. East Afr J Public Health 5, 62-66.

59. WHO Global Database on Anaemia (2007) Data by country on prevalence of anaemia and mean haemoglobin concentration. http://who.int/vmnis/anaemia/data/database/ countries/mar_ida.pdf (accessed June 2013).

60. World Health Organization/Centers for Disease Control and Prevention (2004) Assessing the Iron Status of Populations: Including Literature Reviews. Report of a Joint WHO/CDC Technical Consultation on the Assessment of
Iron Status at the Population Level, Geneva, Switzerland, 6-8 April 2004. Geneva: WHO.

61. Haut Commissariat au Plan (2009) Enquête nationale sur la consommation et les dépenses des ménages 2000-2001. Rapport de synthèse (National Survey of Household Consumption and Expenditure. Summary Report). http:// www.hcp.ma/publication.aspx (accessed May 2010).

62. Özcan MM \& Akbulut M (2008) Estimation of minerals, nitrate and nitrite contents of medicinal and aromatic plants used as spices, condiments and herbal tea. Food Chem 106, 852-858.

63. Pradeep KU, Geervani P \& Eggum BO (1993) Common Indian spices: nutrient composition, consumption and contribution to dietary value. Plant Foods Hum Nutr 44, 137-148. 